\title{
Synthesis of amphiphilic and non-agreggating chlorins from hematoporphyrin using the Diels-Alder reaction
}

\author{
Fabiane A. B. dos Santos, Ana F. Pizzol, Timothy J. Brocksom and \\ Kleber T. de Oliveira
}

Chemistry Department, Universidade Federal de São Carlos - UFSCar, Rodovia Washington Luiz km 235,

São Carlos-SP, 13565-905, Brazil.

*e-mail corresponding author: kleber.oliveira@ufscar.br

Keywords: chlorins, Diels-Alder, Photodynamic Therapy

\section{INTRODUCTION}

Hematoporphyrin (5) (Scheme1) and its derivatives have been extensively studied since the discovery of their potential application as photosensitizers in Photodynamic Therapy (PDT). ${ }^{1}$ This technique is nowadays very promising for treating several diseases such as skin cancer, internal malignant tumors, viral, bacterial and dermatological diseases. Essentially, PDT treatments employ the combined action of a photosensitizer, light, and molecular oxygen to cause selective cellular damage, in which singlet oxygen, generated through a series of photoinduced processes, is believed to be the major cytotoxic agent. ${ }^{2}$ We are exploring the synthesis of new photosensitizers using protoporphyrin IX dimethyl ester (6) obtained from natural hematoporphyrin (5) (Scheme 1). ${ }^{3}$ Porphyrin 6 has been used as diene in the Diels-Alder reaction with phenylmaleimides in order to obtain amphiphilic and non-aggregating compounds. ${ }^{2}$

\section{RESULTS AND DISCUSSION}

First compound $\mathbf{1}$ was protected with ethanedithiol/PTSA (89\% yield) and then reduced with $\mathrm{SnCl}_{2} \cdot 2 \mathrm{H}_{2} \mathrm{O}$ (93\% yield) (Scheme 1). The protected amine 3 was added to maleic anhydride ( $84 \%$ yield) and the amide-ester was converted to 4 using $\mathrm{Ac}_{2} \mathrm{O} / \mathrm{NaOAc}$ with heating $\left(90^{\circ} \mathrm{C}\right)(92 \%$ yield). Protoporphyrin IX dimethyl ester (6) was synthesized from hematoporphyrin (5) performing a double elimination (PTSA $/ \mathrm{C}_{6} \mathrm{H}_{5} \mathrm{Cl}$, reflux, 2h) and a double esterification ( $\mathrm{MeOH} / \mathrm{H}_{2} \mathrm{SO}_{4}$, overnight) $(73 \%$ global yield). The Diels-Alder reaction between porphyrin 6 and phenylmaleimide 4 was performed in toluene at $120^{\circ} \mathrm{C}$ (sealed tube). The endo-adducts 7 and 8 were purified in silica gel (both 14\% yield) and characterized by ${ }^{1} \mathrm{H}$ and ${ }^{13} \mathrm{C}$ NMR and UV-Vis. We will perform deprotection of $\mathbf{7}$ and $\mathbf{8}$ and reaction with some amine-sugars in order to synthesize amphiphilic chlorin derivatives.
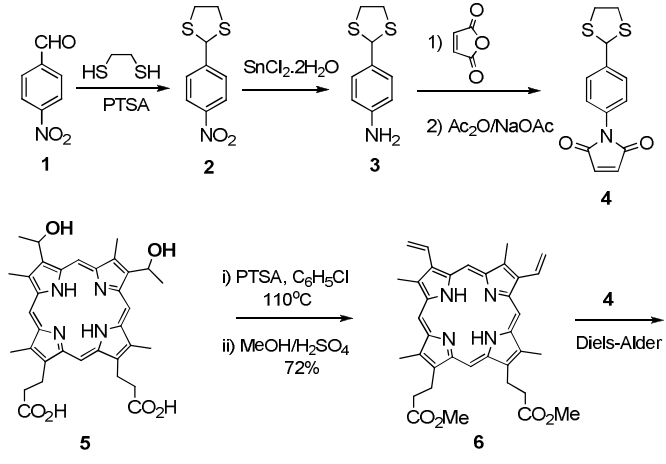

Hematoporphyrin

protoporphyrin IX dimethyl ester

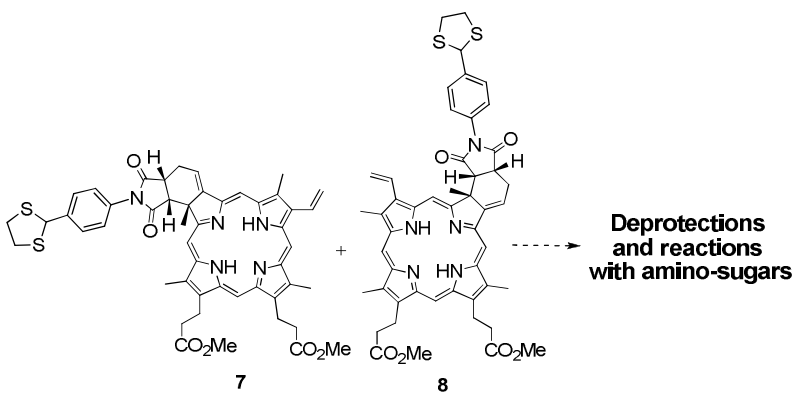

Scheme 1. Synthesis of new chlorin derivatives.

\section{CONCLUSION}

Syntheses of new chlorin derivatives starting from natural hematoporphyrin were performed through the Diels-Alder reaction. The use of the synthesized phenylmaleimides is strategic for the obtainment of adducts with a large group in axial position of the macrocycle, allowing low aggregation in solutions.

\section{ACKNOWLEDGEMENTS}

The authors thank FAPESP (2008/06619-4), CNPq (470338/2010-5) and CAPES for financial support. Thanks are also due to CNPq for scholarship of F.A.B. Santos.

\section{REFERENCES}

${ }^{1}$ de Oliveira, K. T. ; Silva, A. M. S. ; Tome, A. C. ; Neves, M. G. P. M. S Tetrahedron 2008, 648709.

${ }^{2}$ Uchoa, A. F.; Baptista, M. S.; de Oliveira, K. T.; lamamoto, Y.; Serra, O. A.; 2011, requested patent, INPI n 018110004875.

3Jackson, H.A.; Rao, K. R. N.; Wilkins M.; J. Chem. Soc. Perkin Trans., 1987, 1,307 